\title{
FABRICATION OF MEMS DEVICES BY POWDER-FLLING INTO DXRL-FORMED MOLDS
}

TERRY J. GARINO, TODD CHRISTENSON and EUGENE VENTURINI, Sandia National Laboratories, MS-1411, Albuquerque, NM 87185-1411

\begin{abstract}
We have developed a variety of processes for fabricating components for micro devices based on deep x-ray lithography (DXRL). Although the techniques are applicable to many materials, we have demonstrated them using hard $\left(\mathrm{Nd}_{2} \mathrm{Fe}_{14} \mathrm{~B}\right)$ and soft (Ni- $\mathrm{Zn}$ ferrite) magnetic materials because of the importance of these materials in magnetic micro-actuators and other devices and because of the difficulty fabricating them by other means. The simplest technique involves pressing a mixture of magnetic powder and a binder into a DXRL-formed mold. In the second technique, powder is pressed into the mold and then sintered to densify. The other two processes involve pressing at high temperature either powder or a dense bulk material into a ceramic mold that was previously made using a DXRL mold. These techniques allow arbitrary 2-dimensional shapes to be made 10 to $1000 \mu \mathrm{m}$ thick with in-plane dimensions as small as $50 \mu \mathrm{m}$ and dimensional tolerances in the micron range. Bonded isotropic $\mathrm{Nd}_{2} \mathrm{Fe}_{14} \mathrm{~B}$ micromagnets made by these processes had an energy product of 7 MGOe.
\end{abstract}

\section{INTRODUCTION}

The LIGA process has been developed in recent years as a means of producing metal parts in the 10 to $1000 \mu \mathrm{m}$ size range for micro-electromechanical (MEMS) systems. ${ }^{1,2}$ In this process, an $\mathrm{x}$-ray mask, consisting of a pattern of an $\mathrm{x}$-ray absorber such as gold on a low $Z$ support, is used to expose regions of a PMMA layer on a substrate to synchrotron $x$-rays (DXRL). Since synchrotron x-rays are nearly parallel and have high energy, highly precise patterns with straight sidewalls can be formed in a PMMA layer up to $1 \mathrm{~mm}$ thick after exposure and development. Once the PMMA mold is formed, it is filled by plating a metal into the desired regions, utilizing the preexisting plating base. This limits the standard LIGA process to materials that can be electroplated. The excess plated metal is then removed by precision lapping, leaving parts of desired thickness that are then released from the substrate by dissolving the plating base layer.

Permanent (hard) magnet materials have numerous applications in MEMS including microactuators and static field devices such as Halbach arrays. ${ }^{3}$ They are particularly useful because the strength of the magnetic field that they can produce is independent of scale, as opposed to electromagnets where the field scales with length ${ }^{4}$ The hard magnetic materials with the best properties are rare-earth transition metal compounds such as $\mathrm{Nd}_{2} \mathrm{Fe}_{14} \mathrm{~B}$. These materials can have energy products over $40 \mathrm{MGOe}$, over 5 times what can be achieved with other materials. However, they cannot readily be plated because of their complex chemistry and microstructure and therefore cannot be made using the standard LIGA process. Macroscopic magnets of these materials are commercially fabricated in bonded form, which consists of a magnetic powder and an epoxy binder, or, for better properties, in a dense form made by either sintering or hotpressing. ${ }^{6}$ Also, isotropic hot-pressed magnets can be subsequently hot-forged, or die-upset, to create anisotropic magnets with their preferred direction parallel to the pressing direction. ${ }^{6}$

Soft magnetic materials also have applications in MEMS as cores in electromagnets, for example. Since many MEMS devices operate at relatively high frequency, eddy current losses, 


\section{DISCLAIMER}

This report was prepared as an account of work sponsored by an agency of the United States Government. Neither the United States Government nor any agency thereof, nor any of their employees, make any warranty, express or implied, or assumes any legal liability or responsibility for the accuracy, completeness, or usefulness of any information, apparatus, product, or process disclosed, or represents that its use would not infringe privately owned rights. Reference herein to any specific commercial product, process, or service by trade name, trademark, manufacturer, or otherwise does not necessarily constitute or imply its endorsement, recommendation, or favoring by the United States Government or any agency thereof. The views and opinions of authors expressed herein do not necessarily state or reflect those of the United States Government or any agency thereof. 


\section{DISCLAIMER}

Portions of this document may be illegible in electronic image products. Images are produced from the best available original document. 
which increase as the square of the frequency, make metallic soft magnetic materials useless in these situations. The best high frequency soft magnetic materials are ceramic ferrites that have very high electrical resistivity and therefore low eddy current losses. ${ }^{7}$ These materials also cannot be electroplated.

To fabricate micro-components of these magnetic materials, we have developed a variety of processes based on filling DXRL-formed PMMA molds with magnetic powders. ${ }^{8}$ These techniques keep the benefits of the LIGA process (arbitrary shape, small size, high precision, high aspect ratio and batch fabrication) without having the limitation of electroplating.

\section{EXPERIMENT}

The DXRL molds used in this work were fabricated on either Si wafer or alumina substrates. For bonded magnets, a copper release layer $0.5 \mu \mathrm{m}$ thick was sputter coated onto the substrate prior to bonding on the PMMA. The PMMA layers ranged in thickness from 100 to $500 \mu \mathrm{m}$ and were exposed under X-ray masks using a synchrotron facilities at the Center for Advanced Microstructure Devices at Louisiana St. University.

\section{Bonded Magnets}

Both isotropic and anisotropic bonded magnets were fabricated from $\mathrm{Nd}_{2} \mathrm{Fe}_{14} \mathrm{~B}$ powder and epoxy using PMMA DXRL molds on Si wafers with a $\mathrm{Cu}$ release layer. For isotropic magnets, Magnequench MQP-C powder was used. The fabrication process for isotropic magnets is shown in Figure 1. The powder was ground in inert atmosphere and then sieved to 20 to $25 \mu \mathrm{m}$ typically. It was then mixed with a room temperature curing epoxy to give 30 to 40 vol\% epoxy, applied to the mold by a calendering process and then uniaxially pressed at $10 \mathrm{ksi}$.. After curing, the excess material was removed by precision lapping and the PMMA was removed. The parts were then magnetized at $35 \mathrm{kOe}$ using a magnetizer (LDJ Electronincs). Finally, the parts were released by dissolving the release layer in an etchant.

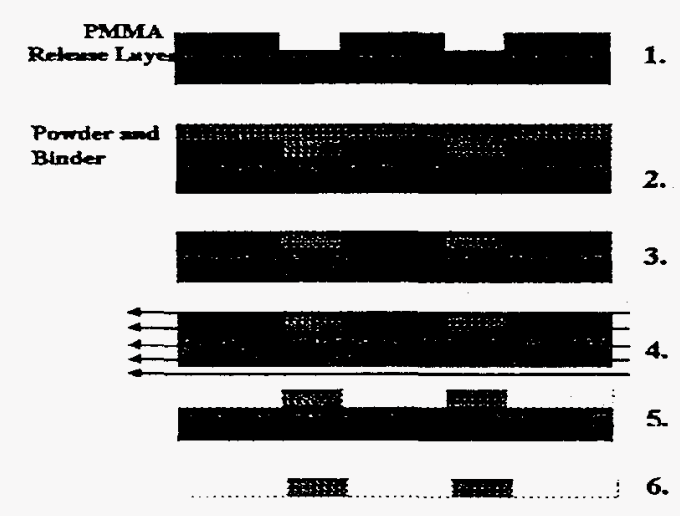

Figure 1. The process for fabricating bonded isotropic magnets from LIGA molds: 1) LIGA mold 2) Apply powder and binder 3) Lap 4) Magnetize

5) Dissolve PMMA and 6) Dissolve release layer.

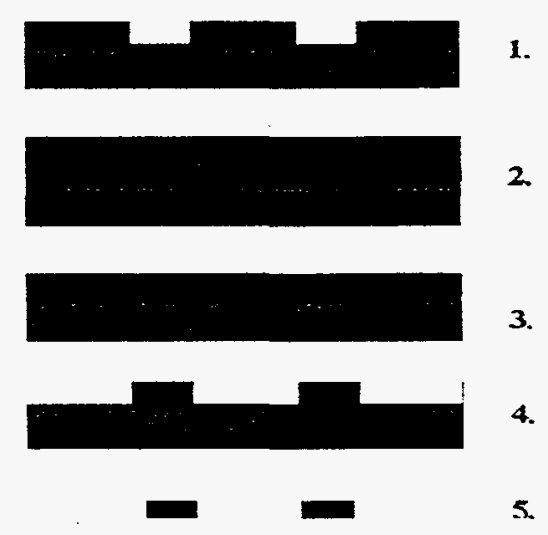

Figure 2. The process for fabricating sintered magnets from LIGA molds: 1) LIGA mold 2) Apply powder 3) Lap 4) Burnout PMMA and 5) Sinter.

A similar process was used to fabricate bonded anisotropic magnets, as shown in Figure 2. In this case, Magnequench MQT (HDDR) powder was used after grinding and magnetizing at 35 kOe. The powder was mixed with epoxy and calendered onto the mold. The mold was then 
placed between the poles of an electromagnet and a field of $10 \mathrm{kOe}$ was applied to align the particles. While the field was on, a clamp was used to compress the aligned powder mixture and it was subsequently pressed at $10 \mathrm{ksi}$ after removal from the field. The rest of the process was the same as for the isotropic case.

\section{Sintered Magnets}

The process used to make sintered micro-magnets is shown in Fig. 3. In this case, a Ni-Zn ferrite powder (Steward, \#xx) was used as received. The powder was mixed with a solvent and a dispersant to form a paste that was then spread onto a PMMA LIGA mold on a Si wafer and dried. The excess powder was removed by lapping and the mold was then heated at $1{ }^{\circ} \mathrm{C} / \mathrm{min}$ in air to $500^{\circ} \mathrm{C}$ to burnout the PMMA. At this point, the parts released from the substrate and were transferred to an alumina plate for sintering. Sintering was done in air at $1300^{\circ} \mathrm{C}$ for $4 \mathrm{hr}$ in a closed crucible that contained an excess of the starting powder to limit $\mathrm{Zn}$ loss.

\section{Hot-Pressed and Hot-Forged Magnets}

To fabricate micro-magnets by hot pressing or hot forging, a mold that can withstand the required pressure and temperature must first be made since a standard PMMA mold is obviously inadequate. Typical hot pressing conditions for $\mathrm{Nd}_{2} \mathrm{Fe}_{14} \mathrm{~B}$ materials are $750^{\circ} \mathrm{C}$ at $15 \mathrm{ksi}$. Since the mold must not deform if precise dimensions are to be maintained, it is desirable that the mold be made of a ceramic such alumina, as most metals will deform severely under these conditions. Therefore, a process, shown in Figure 3, was developed to fabricate alumina molds from PMMA LIGA molds. First, a PMMA LIGA mold with the PMMA in the shapes of the desired magnetic parts on an alumina substrate was fabricated. Alumina powder was applied to the mold either by uniaxial pressing of by slurry casting with or without the aid of a centrifuge. We used a $94 \%$ alumina powder with $2 \mu \mathrm{m}$ average particle size. The excess alumina was removed by lapping and the PMMA was then burned out. The sample was then heated to $1250^{\circ} \mathrm{C}$ in air for $2 \mathrm{hr}$ to give the alumina sufficient strength without causing significant densification, which would distort the desired shapes. Two SEM images of a fired alumina mold with a $250 \mu \mathrm{m}$ thick alumina layer are shown in Figure 4. As can be seen, features in the $100 \mu \mathrm{m}$ range were reproduced with relatively straight sidewalls.

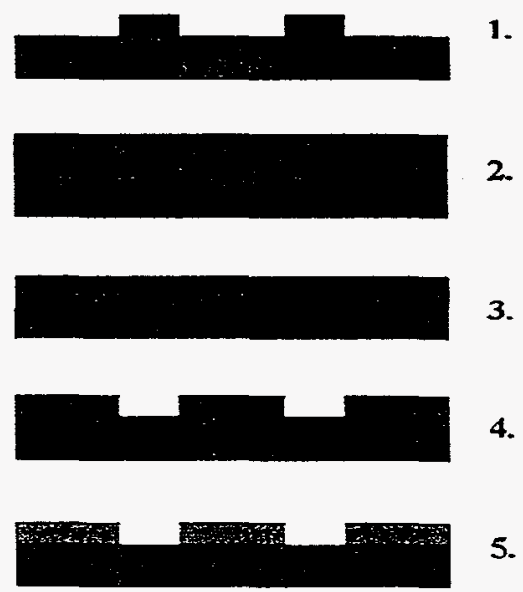

Figure 3. Process for forming a ceramic mold from a LIGA mold: 1) LIGA mold on alumina 2) Apply alumina powder 3) Lap 4) Burnout PMMA and 5) Bisque fire.
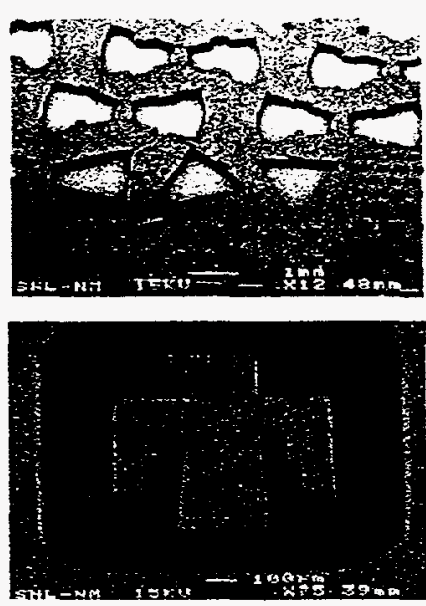

Figure 4. SEM images of a bisque-fired alumina mold made by the process in Fig. 3 for hot pressing and forging. 
The process used to make $\mathrm{Nd}_{2} \mathrm{Fe}_{14} \mathrm{~B}$ micro-magnets by hot-pressing is shown in Figure 5. To form isotropic magnets, MCP-C powder was used after being ground in inert atmosphere to $20 \mu \mathrm{m}$ particle size. A $1 \mu \mathrm{m}$ thick release layer of copper was first sputter coated onto the alumina mold using conditions that maximize sidewall coverage. Copper was chosen because it is inert with respect to the $\mathrm{Nd}_{2} \mathrm{Fe}_{14} \mathrm{~B}$ at the pressing temperature and because it is soluble in a solvent that does not react with the $\mathrm{Nd}_{2} \mathrm{Fe}_{14} \mathrm{~B}$. A layer of the powder about $2 \mathrm{~mm}$ thick was pressed onto the mold at room temperature and the

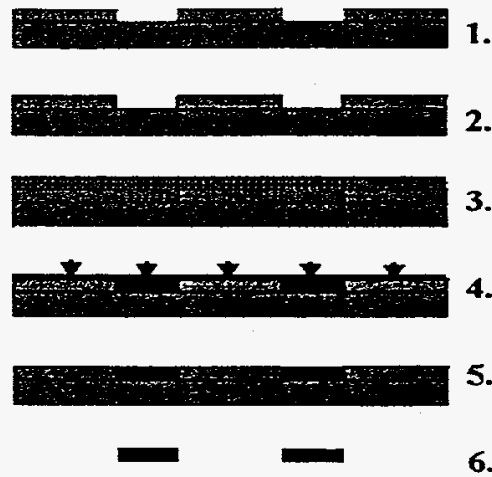

Figure 5. The process for fabricating micro-magnets by hot-pressing: 1) Ceramic mold 2) Coat with release layer 3) Apply powder 4) Hot-press 5) Lap and magnetize and 6) Dissolve release layer.

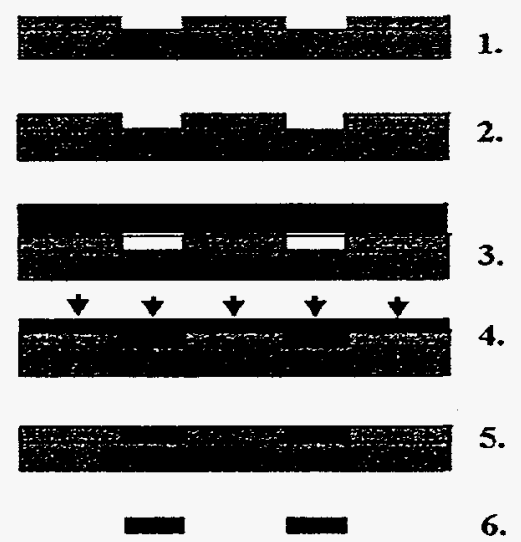

Figure 6. The process for fabricating hot-forged micro-magnets: 1) Ceramic mold 2) Coat with release layer 3) Apply slice of bulk magnet 4) Hot-forge 5) Lap and magnetize and 6) Dissolve release layer.

sample was then heated under high vacuum to $700^{\circ} \mathrm{C}$ at which time a compressive stress of 10 $\mathrm{ksi}$ was applied for $30 \mathrm{~min}$. After cooling, the excess material was lapped off and the sample was magnetized. Finally, the copper layer was dissolved in ammonium hydroxide to release the parts. Anisotropic magnets were made by a similar process using powder formed by regrinding a bulk $\mathrm{Nd}_{2} \mathrm{Fe}_{14} \mathrm{~B} \mathrm{MQP}-3$ magnet from Magnequench to a $20 \mu \mathrm{m}$ particle size. This is an anisotropic material that was made by hot-pressing and then die-upsetting a melt-spun powder. The powder was then magnetized and placed on the copper coated alumina mold in a $10 \mathrm{kOe}$ field to align the particles. The powder was then vacuum hot-pressed, lapped, magnetized and released as described above.

The hot-forging process developed to make $\mathrm{Nd}_{2} \mathrm{Fe}_{14} \mathrm{~B}$ micro-magnets is shown in Figure 6. The process is essentially identical to the hot-pressing process except that a dense slice of Magnequench MQP-3 magnet $2 \mathrm{~mm}$ thick was used instead of powder. The slice was oriented with its preferred direction parallel to the plane of the substrate in the desired direction with respect to the shapes of the parts.

\section{RESULTS}

Bonded isotropic micro-magnets are shown in Figure 7. Shapes with high dimensional tolerance with features below $100 \mu \mathrm{m}$ were formed as thick as $0.5 \mathrm{~mm}$. A SQUID magnetometer was used to measure the magnetic hysteresis loop for some of the parts. The measurements indicated that the isotropic magnets had an energy product of 7 MGOe. 

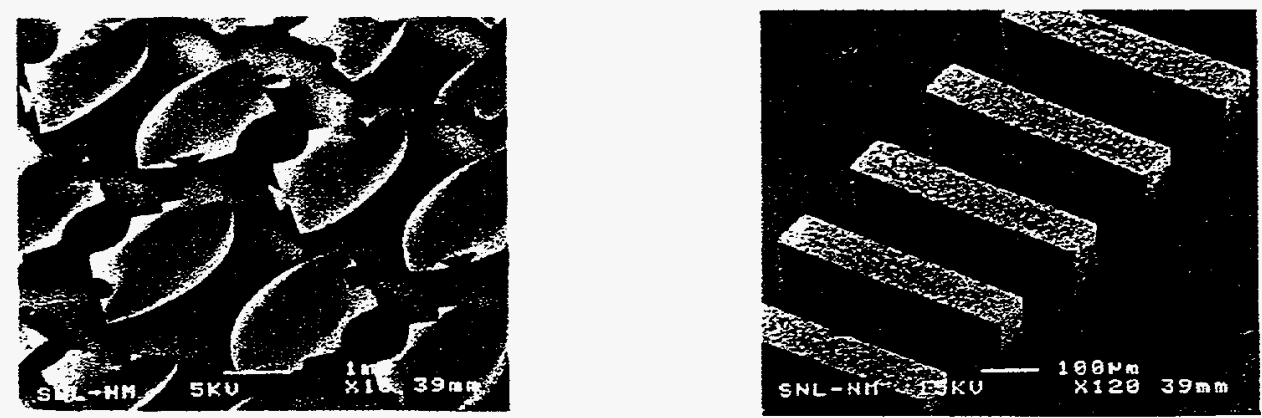

Figure 7. SEM micrographs of isotropic bonded micromagnets.

Two SEM images of a micro-toroid of $\mathrm{Ni}$ - Zn ferrite made by the sintering process are shown in Figure 8. The toroid has an OD of $800 \mu \mathrm{m}$ and a wall thickness of $80 \mu \mathrm{m}$, indicating that $20 \%$ linear shrinkage occurred during sintering since the initial dimensions were $1 \mathrm{~mm}$ and $100 \mu \mathrm{m}$, respectively. The micrograph indicates that full density was achieved with an average grain size of about $15 \mu \mathrm{m}$, a microstructure that produces optimal properties in this materials. Also, no distortion occurred to the circular shape of the toroid during processing.
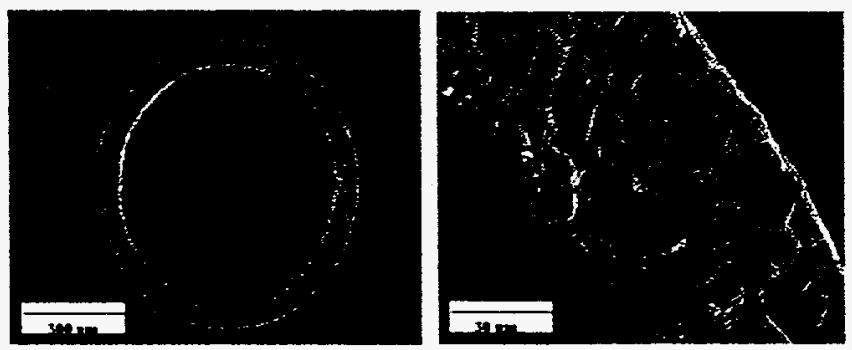

Figure 8. SEM micrographs of a $\mathrm{Ni}-\mathrm{Zn}$ ferrites micro-toroid made using sintering-DXRL process.

The hot-pressing and hot-forging processes were developed as ways to produce dense parts without the in-plane shrinkage that occurs during sintering so that higher precision could be achieved. If the mold used in these processes is rigid, as we believe it was for the alumina molds, then the part tolerance is determined by the initial mold tolerance. This is in turn set by any distortion that occurs during bisque-firing of the mold. We noticed a slight sloping of the sidewalls on our alumina molds. Using hot-forging, parts $100 \mu \mathrm{m}$ wide and $250 \mu \mathrm{m}$ thick were fabricated using the following pressing conditions: $800^{\circ} \mathrm{C}, 15 \mathrm{ksi}$ for $1 \mathrm{hr}$.

Each of the four techniques developed has their own relative advantages and disadvantages. The bonded magnet technique is the simplest and yields the most precise parts. However, it gives the worst magnetic properties due to the presence of the bonding phase. The sintering method is also relatively simple and it can produce dense parts with excellent properties. However, dimensional change due to sintering shrinkage must be compensated for in mask design and final part dimensional tolerance is decreased due to shrinkage variability. The hotpressing and hot-forging techniques are the most difficult since they require the fabrication of a ceramic mold and the use of a hot-press. However, they yield excellent properties and have the potential for excellent dimensional tolerance if the tolerance of the ceramic mold is optimized.

\section{CONCLUSIONS}

Four processes have been developed for fabricating both hard and soft micro-magnets based on the LIGA process. They were used to make magnets with precise dimensions in the 100 to $1000 \mu \mathrm{m}$ range with excellent magnetic properties. Finally, these processes are applicable to 
many other materials that may be useful in MEMS applications that cannot be made using the traditional LIGA technique.

\section{ACKNOWLEDGMENTS}

This work was performed at Sandia National Laboratories, a multiprogram laboratory operated by Sandia Corp., a Lockheed Martin company, for the US Department of Energy under contract DE-AC04-84AI.85000.

\section{REFERENCES}

1. H Guckel, Proc. of the IEEE, 86 p. 1586 (1998).

2. T.R. Christenson and H. Guckel, in Proceedings SPIE Micromachining and Microfabrication Process Technology, 2639 p. 134 (1995).

3. T.R Christenson, T.J. Garino, E.L. Venturini, “Deep X-Ray Lithography Based Fabrication of Rare-Earth Based Permanent Magnets and their Applications to Microactuators," to be published in the Fifth International Symposium on Magnetic Materials, Processes and Devices, from the $194^{\text {th }}$ Meeting of the Electrochemical Society, 1998.

4. K. Halbach, in High Performance Permanent Magnets/1987, Edited by S.G. Sankar, J.F. Herbst and N.C. Koon (Mater. Res. Soc. Proc. 96, Pittsburgh, PA 1987), p.259.

5. J.M.D. Coey in Rare-Earth Iron Permanent Magnets, edited by J.M.D. Coey (Clarendon Press, Oxford 1996), p. 9.

6. I.R Harris in Rare-Earth Iron Permanent Magnets, edited by J.M.D. Coey (Clarendon Press, Oxford 1996), p. 353-70.

7. A. Goldman, Modern Ferrite Technology, Van Nostrand Reinhold, New York, 1990, pp. 6775.

8. H.-J. Ritzhaupt-Kleissel, W. Bauer, E. Gunther, J. Laubersheimer and J. HauBelt, Microsystem Technologies 2, p. 1301 (1996).

9. Reference 7, pp. 116.31. 